\title{
Empirical Comparative Study of Wearable Service Trust Based on User Clustering
}

\author{
Zhongwei Gu, Shanghai Dianji University, China \\ Hongjun Xiong, Shanghai Dianji University, China \\ Wei Hu, Shanghai University of Electric Power, China
}

\begin{abstract}
Users of wearable services are different in age, occupation, income, education, personality, values, and lifestyle, which also determine their different consumption patterns. Therefore, for the trust of wearable services, the influencing factors or strength may not be the same for different users. This article starts with the resource and motivation dimensions of VALSTM model, and the clustering model and questionnaire scale for consumers of wearable services were constructed. And then the users and potential users of wearable service are clustered by an improved clustering algorithm based on adaptive chaotic particle swarm optimization. Through clustering analysis of 535 valid questionnaires, users are grouped into three types of consumers with different lifestyles, respectively named trend-following users, fashion-leading users, and economic-rational users. Finally, this paper analyzes and compares the trust subgroup models of three clusters and draws some conclusions.
\end{abstract}

\section{KEYWORDS}

Clustering, Empirical Comparison, Trust, Wearable Services

\section{INTRODUCTION}

Wearable devices are not only hardware, but also a comprehensive service combining hardware and software. Wearable services refer to new service models that can be applied in health, entertainment, social business and other fields by comprehensively applying various wearable devices and related technologies and having the capability of situational computing and natural interaction (Gu,2020). Wearable services are an important link connecting people to the "Internet of Things", as well as an important data source in the era of big data.

For a new service, different consumers consider different factors before making a decision about whether to use it, so there is a great deal of uncertainty, but it is often accompanied by trust issues. Wearables users vary in age, occupation, income, education, personality, values and lifestyle, which also determine their consumption patterns. Therefore, for the trust of wearable services, the influencing factors or strength may not be the same for different users.

In this paper, an improved clustering algorithm based on adaptive chaotic particle swarm optimization and consumer characteristic data are combined to establish a consumer clustering model for wearable services. According to the clustering model, the target users are grouped. Then, the structural equation is used to conduct empirical analysis on the overall model and different subgroup models of wearable service consumers trust based on user clustering, so as to find out the key factors

DOI: 10.4018/JOEUC.20211101.oa18

This article published as an Open Access article distributed under the terms of the Creative Commons Attribution License (http://creativecommons.org/licenses/by/4.0/) which permits unrestricted use, distribution, and production in any medium, provided the author of the original work and original publication source are properly credited. 
affecting wearable service trust, the particularity of wearable service consumer behavior and the difference of influencing factors of different subgroup clusters of trust, and analyze the reasons and propose countermeasures.

\section{CLUSTERING MODEL DESIGN}

To conduct clustering analysis of wearable service consumers, a clustering model of wearable service consumers should be constructed first, including the model's constituent elements (clustering variables) and the relationship between elements (model structure).

\subsection{Clustering Variables}

The traditional user clustering or market segmentation variables are mainly based on demographic characteristics, but this method has great limitations, and cannot accurately classify user groups, let alone effectively predict customer behavior. Since the 1970s, many scholars and experts began to use psychological characteristics to study consumer behavior and user segmentation, among which the more important method is based on consumer "lifestyle". Lifestyle is measured mainly by using the mental map method. The research on the application of mental maps mainly includes the VALS (Values and Life Style Survey) method, which is currently popular, and the modified VALS ${ }^{\mathrm{TM}}$ (Dale et al., 2011) methods.

According to the previous research results of experts on individual psychological characteristics (Wang et al., 2013; Wayne et al., 2010; Luo et al., 2007) and VALS ${ }^{\mathrm{TM}}$, the variables of the clustering model of wearable service consumers in this paper come from two dimensions: the horizontal dimension is the resource dimension and the vertical dimension is the motivation dimension, which are as follows:

\section{Resource Dimension}

Demographic variables: gender, age, education, occupation, income

Personality characteristics: (a) Ability: Energy, intelligence, leadership; (b) Personality: curiosity, self-confidence, impulse

\section{Motivation Dimension}

It can be divided into three motivations: ideal motivation, achievement motivation and self-expression motivation.

\subsection{Clustering Model}

The 14 variables extracted from the above two dimensions constitute a part of the clustering model in this paper. The data required by the clustering model are collected by questionnaire. The specific measurement items of the scale are shown in Table 1 . Then, data processing is carried out on the WEKA data mining platform based on our improved data mining algorithm. The processing flow of the clustering model is shown in Figure 1:

\subsection{Algorithm Selection}

The clustering model has been established, and the next step is how to select the appropriate clustering algorithm for clustering analysis. Classical clustering algorithms include fuzzy c-means, PSO-c-means, k-means etc. Among them, fuzzy c-means clustering algorithm is widely studied and applied. Fuzzy c-means clustering algorithm is effective in processing small-scale low-dimensional data sets, but the algorithm performance in dealing with high dimensional data set from the adaptability is not strong, easy to fall into local minimum values and cluster effect is not ideal. To solve this problem, this paper uses an improved clustering algorithm based on adaptive chaotic particle swarm optimization 
Figure 1. Cluster Model Flow Diagram

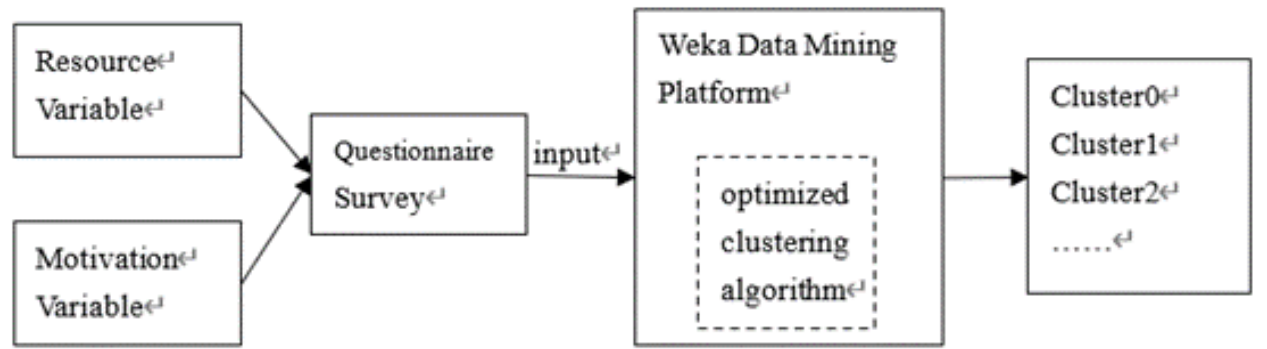

Table 1. Study Variables and Indicators of Cluster Variables

\begin{tabular}{|c|c|c|c|c|c|}
\hline \multicolumn{3}{|c|}{ Variable } & Indicators & Items & Sources \\
\hline \multirow[t]{15}{*}{ Resource } & \multicolumn{2}{|c|}{ Demographic Characteristics } & IC1 - IC5 & Gender, Age, Income, Occupation, Education & (Wang,2013) \\
\hline & \multirow[t]{6}{*}{ Ability } & \multirow[t]{2}{*}{ Energy } & IC6 & I have enough energy to learn new things and technologies & (Wang,2013) \\
\hline & & & IC7 & I have enough time to learn new things and technologies & (Wang,2013) \\
\hline & & \multirow[t]{2}{*}{ Intelligence } & IC 8 & I think it's easy for me to accept new things or learn new skills & (Wang,2013) \\
\hline & & & IC9 & I think the steps of using the new technology are very simple & (Wang,2013) \\
\hline & & \multirow[t]{2}{*}{ Leadership } & $\mathrm{IC} 10$ & $\begin{array}{l}\text { My friends and family often ask me for advice on how to use new } \\
\text { technologies }\end{array}$ & (Wang,2013) \\
\hline & & & IC11 & My advice will have an impact on the people around me & (Wang,2013) \\
\hline & \multirow[t]{8}{*}{ Character } & \multirow[t]{3}{*}{ Curiosity } & $\mathrm{IC} 12$ & $\begin{array}{l}\text { I am always curious about new technology and new things and } \\
\text { want to try them }\end{array}$ & (Wang,2013) \\
\hline & & & $\mathrm{IC} 13$ & Every time a new technology or product comes out, try it & (Wang,2013) \\
\hline & & & IC14 & Every time a vendor launches a new business, I want to try it out & (Wang,2013) \\
\hline & & \multirow{2}{*}{$\begin{array}{l}\text { Self- } \\
\text { Confidence }\end{array}$} & IC15 & I have the ability to master a new technology or a new thing & (Wang,2013) \\
\hline & & & IC16 & $\begin{array}{l}\text { When using Internet services, I always stick to my opinion } \\
\text { regardless of the opposition of others }\end{array}$ & (Wang,2013) \\
\hline & & \multirow[t]{3}{*}{ Impulse } & $\mathrm{IC} 17$ & $\begin{array}{l}\text { When I buy something, I always compare prices. I only buy items } \\
\text { that are good value for money }\end{array}$ & (Wang,2013) \\
\hline & & & $\mathrm{IC} 18$ & $\begin{array}{l}\text { Their idols to do the endorsement of the goods are very want to } \\
\text { buy }\end{array}$ & (Wang,2013) \\
\hline & & & IC19 & $\begin{array}{l}\text { You used to think something was bad, but as more and more } \\
\text { people around you bought it, you thought it was good }\end{array}$ & (Wang,2013) \\
\hline \multirow[t]{6}{*}{ Motivation } & & \multirow{2}{*}{$\begin{array}{l}\text { Ideal } \\
\text { Motivation }\end{array}$} & IC20 & I always buy a product after careful consideration and comparison. & New item \\
\hline & & & $\mathrm{IC} 21$ & What I like most is the function and reliability of the product & (Wayne, 2010) \\
\hline & & \multirow{2}{*}{$\begin{array}{l}\text { Achievement } \\
\text { Motivation }\end{array}$} & IC22 & I am very easily influenced by the actions and opinions of others. & (Wayne,2010) \\
\hline & & & IC23 & Using wearable services is a status symbol. & (Wayne, 2010) \\
\hline & & \multirow{2}{*}{$\begin{array}{l}\text { Self-Expression } \\
\text { Motivation }\end{array}$} & IC24 & Using a wearable device gives me more face and personality. & (Wayne,2010) \\
\hline & & & $\mathrm{IC} 25$ & $\begin{array}{l}\text { Using wearable devices can make me more fashionable and } \\
\text { popular, the price is secondary. }\end{array}$ & (Wayne,2010) \\
\hline
\end{tabular}


(Gu,2015), and theoretical analysis and experimental results show that the clustering effect is superior to the existing c-means, standard PSO and other algorithms.

\section{CONSUMER LIFESTYLE CLUSTERING}

\subsection{Data Collection}

We adopted a combination of online and offline questionnaires, and selected some undergraduates,

Table 2. Sample Characteristics of the Questionnaire

\begin{tabular}{|c|c|c|c|c|c|c|c|}
\hline Item & scale & Frequency & Percent $(\%)$ & Item & scale & Frequency & Percent $(\%)$ \\
\hline \multirow[t]{2}{*}{ Gender } & male & 270 & 50.5 & \multirow[t]{5}{*}{ Occupation } & teacher & 50 & 9.3 \\
\hline & female & 265 & 49.5 & & student & 206 & 38.5 \\
\hline \multirow[t]{5}{*}{ Age } & $<18$ & 13 & 2.5 & & $\begin{array}{l}\text { company } \\
\text { staff }\end{array}$ & 144 & 26.9 \\
\hline & & & & & engineer & 77 & 14.4 \\
\hline & $18--24$ & 281 & 52.5 & & others & 58 & 10.9 \\
\hline & $25--35$ & 198 & 37.0 & \multirow{4}{*}{$\begin{array}{l}\text { Experience } \\
\text { with } \\
\text { Wearable } \\
\text { Devices }\end{array}$} & never heard & 101 & 18.9 \\
\hline & $>36$ & 43 & 8.1 & & $\begin{array}{l}\text { heard but not } \\
\text { used }\end{array}$ & 375 & 70.1 \\
\hline \multirow{6}{*}{$\begin{array}{l}\text { Education } \\
\text { Level }\end{array}$} & \multirow{2}{*}{$\begin{array}{l}\text { high school and } \\
\text { below }\end{array}$} & \multirow[t]{2}{*}{26} & \multirow[t]{2}{*}{4.9} & & used & 58 & 10.9 \\
\hline & & & & & others & 1 & 0.0 \\
\hline & college & 64 & 12.0 & \multirow{4}{*}{$\begin{array}{l}\text { Monthly } \\
\text { Income } \\
\text { Level }\end{array}$} & $<2000$ & 188 & 35.1 \\
\hline & undergraduate & 391 & 73.1 & & $2000-5000$. & 183 & 34.2 \\
\hline & \multirow[t]{2}{*}{ master and above } & \multirow[t]{2}{*}{54} & \multirow[t]{2}{*}{10.2} & & $5000-8000$. & 108 & 20.2 \\
\hline & & & & & $>8000$ & 56 & 10.5 \\
\hline
\end{tabular}

graduate students and professionals in Chinese domestic IT industry. These two groups have a high usage rate of handheld devices and wearable devices, which contribute a lot to the accuracy of the study. A total of 712 questionnaires were recovered, including 535 valid questionnaires. The effective recovery rate was $75.1 \%$. The sample characteristics of the questionnaire are shown in Table 2.

\subsection{Process of Consumers' Lifestyle Clustering}

According to the clustering model designed in Section 2.2, 14 variables such as gender, age, education, occupation, income, energy, intelligence, leadership, curiosity, self-confidence, impulse, ideal motivation, achievement motivation and self-expression motivation were taken as clustering variables, and the cluster number was determined as three. Java language was used to implement the adaptive chaotic particle swarm optimization clustering algorithm and integrated into WEKA3.8 data mining platform as a plug-in.1

In the pre-processing stage, the data sources are extracted, cleaned, transformed and then loaded into WEKA, as shown in Table 3.

After data training, three clusters were finally obtained, as shown in Figure 2. The values of the three clusters are the average values of 25 measures of IC1-IC25 respectively. It can be seen from 
Table 3. Consumer Lifestyle Data (CVS Format)

\begin{tabular}{|l|l|l|l|l|l|l|l|l|l|l|l|l|}
\hline IC1 & IC2 & IC3 & IC4 & IC5 & IC6 & IC7 & IC8 & IC9 & IC10 &.. & IC24 & IC25 \\
\hline male & $18-24$ & $>12000$ & student & undergraduate & 7 & 7 & 7 & 7 & 7 & $\ldots$ & 7 & 7 \\
\hline male & $18-24$ & $\begin{array}{l}2000- \\
4999\end{array}$ & staff & undergraduate & 4 & 4 & 4 & 4 & 6 & $\ldots$ & 7 & 7 \\
\hline$\ldots$ & $\ldots$ & & & & & & & & & & & $\ldots$ \\
\hline
\end{tabular}

Figure 2. Clustering Results

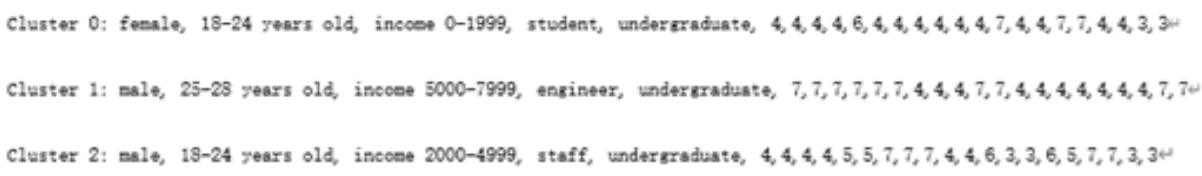

the results that the clustering results are differentiated well. The specific interpretation is described in detail in the following section.

\subsection{Naming of Clusters}

According to the clustering results in Figure 2, three clusters were named respectively, they are trendfollowing users, fashion-leading users and economic-rational users.

\section{(1) Trend-following Users}

As shown in Table 4, this kind of users are mainly female college students. They are curious, impulsive and like to follow social trend. Their personalities are relatively weak and they are easily influenced by others, so they will also pay attention to the trend.

\section{(2) Fashion-leading Users}

As shown in Table 5, this kind of user are mainly male engineers with moderate income and strong energy, intelligence, leadership, self-confidence and self-expression motivation. Therefore, this paper named this kind of user as fashion-leading users.

\section{(3) Economic-rational Users}

As shown in Table 6, these users are mainly male employees with low income and are not easy to be impulsive. They have a rational view of functional adaptation, a strong sense of consumption economy, shop around and pursue a practical life attitude rather than impulsive purchase and pay attention to price. Therefore, this paper names these users as economic-rational users.

Next, this study attempts to use the above three clustering subgroups as the basis for market segmentation to understand the views and behaviors of consumers with different lifestyles, and to compare whether the strength and direction of the relationship between variables in the trust model have changed in three different consumer samples. 

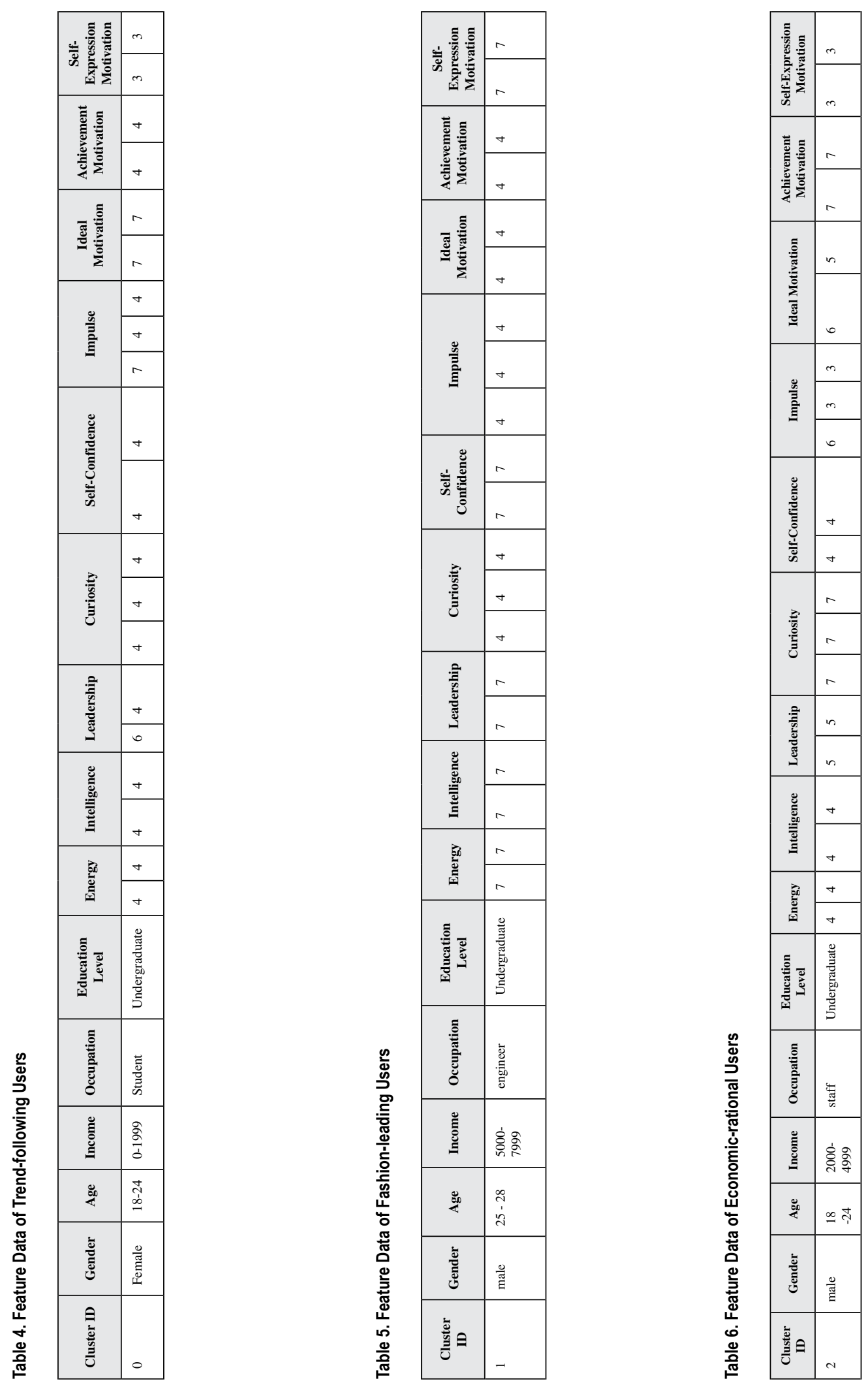
Table 7. Model Fitting Index

\begin{tabular}{|l|l|l|l|l|l|l|l|}
\hline & $\mathbf{x} 2 / \mathbf{d f}$ & RMSEA & GFI & AGFI & CFI & NFI & IFI \\
\hline Recommended Values & $<3$ & $<0.08$ & $>0.90$ & $>0.80$ & $>0.90$ & $>0.90$ & $>0.90$ \\
\hline Empirical Values & 3.59 & 0.07 & 0.74 & 0.69 & 0.95 & 0.93 & 0.95 \\
\hline
\end{tabular}

\section{MODEL HYPOTHESIS TESTING FOR DIFFERENT CLUSTERS}

This section will focus on whether different personal lifestyles will influence the assumptions of the trust model and produce different path coefficients.

\subsection{Overall Trust Model Before Clustering}

Through the author's previous research $(\mathrm{Gu}, 2020 ; \mathrm{Gu}, 2017 ; \mathrm{Gu}, 2016)$ and a large number of literature studies(Sarah,2012; Huang,2014; Gefen,2000; Junglas,2006; McKnight,2002) by combining the specific factors influencing the initial trust of wearable services with the model of UTAUT2 theory, we explored the antecedent variables of wearable devices' trust and constructed an overall integrated conceptual model of initial trust of wearable services. Then, through 535 valid questionnaire data, empirical analysis was conducted, and the results were as follows:

$\operatorname{Alpha}(\boldsymbol{\alpha})$ value of the overall integrated model is 0.951 , and the overall reliability is good. KMO value was 0.876 , and the associated probability was 0.000 , which was less than the significance level of 0.05 .Through exploratory factor analysis, 18 factors with the characteristic value greater than 1 were separated out, the variance interpretation rate was $80.701 \%$, the factor structure was clear, the factor load value of each item on its associated variables was greater than 0.5 , and the factor load of crossover variables did not exceed 0.5 , indicating that the scale had good convergence validity and discriminant validity. The structural equation modeling software Lisrel8.72 was used to test each path hypothesis in the research model, and the results were shown in Figure 3.

According to $\mathbf{t}$ value obtained from the experiment, the research results show that the sample data supports 13 of the 18 hypotheses of the model. The specific hypothesis is as follows:

1) At the $\mathrm{p}<0.05$ level, the hypothesis that were not significant were: H9(SI-IT), H12(PV-IT), H6(SC-IT), H1c (P-DT), and H1d (I-DT).

2) At $\mathrm{p}<0.05$ level $(*)$, significant hypothesis were: H8(EE-IT) and H13(HT-IT).

3) At $\mathrm{p}<0.01$ level (**), Significant hypothesis were: H10(FC-IT), H3(SA-IT), H1b (F-DT).

4) At $\mathrm{p}<0.001$ level(***), significant hypothesis were: H7(PE-IT), H11(HM-IT), H5(PC-IT), H4(TP-IT), H2(FR-IT), H1(DT-IT), H14(IT-UI), H1a (W-DT).

The above relationship is marked in Figure 3. Six factors, including performance expectancy, hedonic motivation, privacy concern, trust propensity, firm reputation and device trust, significantly affect consumers' initial trust in wearable services. the influence of social influence, price value, security concern and other three factors is not significant, while the remaining four factors have certain influence. The important antecedents of trust in wearable devices include wearability and functionality, while the influence of antecedents such as personalization and integration are not significant.

Lisrel software also gives the fitting indexes of the structural equation model, as shown in Table 7. Where, the ratio of chi-square value to degrees of freedom is 3.59. According to the suggestions of Joreskog et al., the result is good and the value is acceptable. RMSEA (Root Mean Square Error of Approximation) is the root of approximation error, and the smaller the value is, the better the fit degree of the model is. For other indicators, such as GFI(Goodness of Fit Index), AGFI(Adjusted Goodness of Fit Index), CFI(Comparative Fit Index),NFI(Normed Fit Index), the higher the value 
Figure 3. Lisrel Analysis Results of the Overall Trust Model Before Clustering ( $P<0.05$, ${ }^{* *} P<0.01$, ** $P<0.001$ )

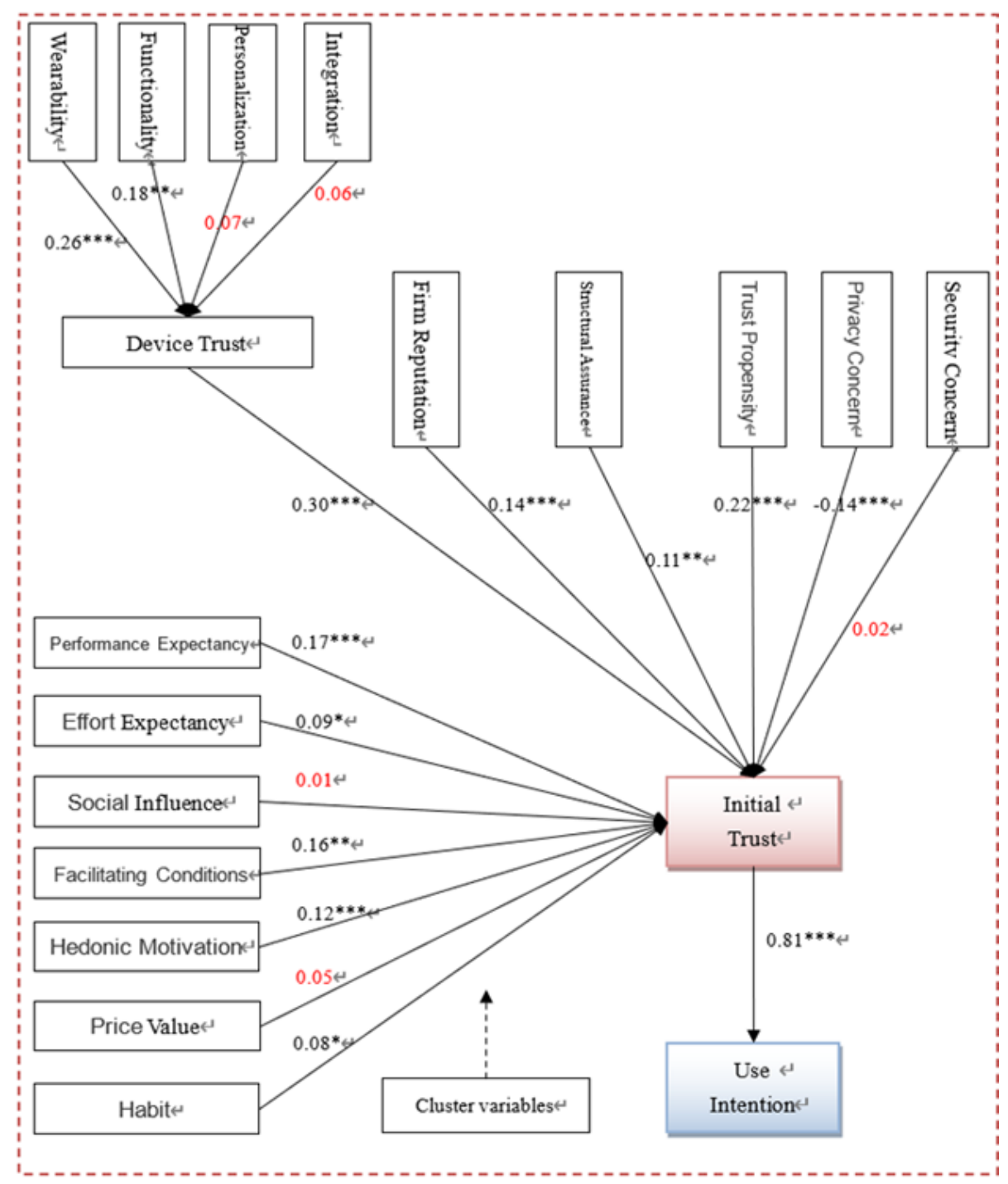

of these indicators, the better the model fitting data will be. By comparing the recommended value with the value obtained by the model in this study, it can be seen that some indexes of model fitting degree in this paper are not so good but generally acceptable.

\subsection{Subgroup Trust Model Based on Clustering}

In order to verify the differences in trust factors of consumer wearable services in different clusters, this study divides the samples into three subgroups according to the results of clustering analysis above, namely, trend-following users, fashion-leading users and economic-rational users. Then Lisrel was used to test each path hypothesis in the three sub-models respectively. The path coefficients were listed in the order of three types of users, and the results were shown in Figure 4. 
Table 8. Comparison of three subgroup models of different clusters

\begin{tabular}{|c|c|c|c|c|c|c|}
\hline \multirow[t]{2}{*}{ Variable } & \multirow[t]{2}{*}{ ID } & \multirow[t]{2}{*}{ Hypothesis } & \multicolumn{3}{|c|}{ Standard Regression Coefficient } & \multirow[b]{2}{*}{ Overall } \\
\hline & & & Trend-following & $\begin{array}{c}\text { Fashion- } \\
\text { leading }\end{array}$ & $\begin{array}{c}\text { Economic } \\
\text {-rational }\end{array}$ & \\
\hline Device Trust & $\mathrm{H} 1$ & $\begin{array}{l}\text { Device trust significantly } \\
\text { affects consumers' initial trust } \\
\text { in wearable services. }\end{array}$ & 0.12 & 0.45 & 0.09 & 0.30 \\
\hline Wearability & H1a & $\begin{array}{l}\text { Wearability significantly } \\
\text { affects consumers' trust in } \\
\text { wearable devices. }\end{array}$ & 0.28 & 0.26 & 0.25 & 0.26 \\
\hline Functionality & $\mathrm{H} 1 \mathrm{~b}$ & $\begin{array}{l}\text { Functionality has a significant } \\
\text { impact on consumers' trust in } \\
\text { wearable devices. }\end{array}$ & 0.05 & 0.32 & 0.16 & 0.18 \\
\hline Personalization & $\mathrm{H} 1 \mathrm{c}$ & $\begin{array}{l}\text { Personalization has a } \\
\text { significant impact on } \\
\text { consumers' trust in wearable } \\
\text { devices. }\end{array}$ & 0.11 & 0.16 & 0.15 & 0.07 \\
\hline Integration & H1d & $\begin{array}{l}\text { Integration significantly } \\
\text { affects consumers' trust in } \\
\text { wearable devices. }\end{array}$ & 0.12 & 0.01 & 0.11 & 0.06 \\
\hline Firm Reputation & $\mathrm{H} 2$ & $\begin{array}{l}\text { The reputation of the firm has } \\
\text { a significant impact on the } \\
\text { initial trust of the wearable } \\
\text { services. }\end{array}$ & 0.03 & 0.19 & 0.49 & 0.14 \\
\hline Structural Assurance & $\mathrm{H} 3$ & $\begin{array}{l}\text { Structural assurance will } \\
\text { positively affect consumers' } \\
\text { initial trust in wearable } \\
\text { services. }\end{array}$ & 0.10 & 0.08 & 0.11 & 0.11 \\
\hline Trust Propensity & $\mathrm{H} 4$ & $\begin{array}{l}\text { Consumers' trust propensity } \\
\text { significantly affects initial } \\
\text { trust in wearable services. }\end{array}$ & 0.30 & 0.08 & 0.15 & 0.22 \\
\hline Privacy Concern & H5 & $\begin{array}{l}\text { Privacy concerns negatively } \\
\text { affect consumers' initial trust } \\
\text { in wearable services. }\end{array}$ & 0.21 & 0.10 & 0.28 & 0.14 \\
\hline Security Concern & H6 & $\begin{array}{l}\text { Security concerns negatively } \\
\text { affect consumers' initial trust } \\
\text { in wearable services. }\end{array}$ & 003 & 0.04 & 0.17 & 0.02 \\
\hline Performance Expectancy & H7 & $\begin{array}{l}\text { Performance expectancy } \\
\text { have a positive impact on } \\
\text { consumers' initial trust in } \\
\text { wearable services. }\end{array}$ & 0.25 & 0.13 & 0.02 & 0.17 \\
\hline Effort Expectancy & $\mathrm{H} 8$ & $\begin{array}{l}\text { Efforts are expected to } \\
\text { positively affect consumers' } \\
\text { initial trust in wearable } \\
\text { services. }\end{array}$ & 0.06 & 0.22 & 0.14 & 0.09 \\
\hline Social Influence & H9 & $\begin{array}{l}\text { Social influence positively } \\
\text { affects consumers' initial trust } \\
\text { in wearable services. }\end{array}$ & 0.11 & 0.01 & 0.08 & 0.01 \\
\hline Facilitating Conditions & $\mathrm{H} 10$ & $\begin{array}{l}\text { Facilitating conditions } \\
\text { positively affect consumers' } \\
\text { initial trust in wearable } \\
\text { services. }\end{array}$ & 0.13 & 0.18 & 0.03 & 0.16 \\
\hline Hedonic Motivation & H11 & $\begin{array}{l}\text { Hedonic motivation positively } \\
\text { affects consumers' initial trust } \\
\text { in wearable services. }\end{array}$ & 0.18 & 0.04 & 0.07 & 0.12 \\
\hline Price Value & $\mathrm{H} 12$ & $\begin{array}{l}\text { Price value negatively affects } \\
\text { consumers' initial trust in } \\
\text { wearable services. }\end{array}$ & 0.01 & 0.02 & 0.26 & 0.05 \\
\hline Habit & H13 & $\begin{array}{l}\text { Habits positively affect } \\
\text { consumers' initial trust in } \\
\text { wearable services. }\end{array}$ & 0.13 & 0.09 & 0.02 & 0.08 \\
\hline Initial Trust & H14 & $\begin{array}{l}\text { Consumers' initial trust } \\
\text { positively affects consumers' } \\
\text { willingness to use wearable } \\
\text { services. }\end{array}$ & 0.82 & 0.85 & 0.82 & 0.81 \\
\hline
\end{tabular}




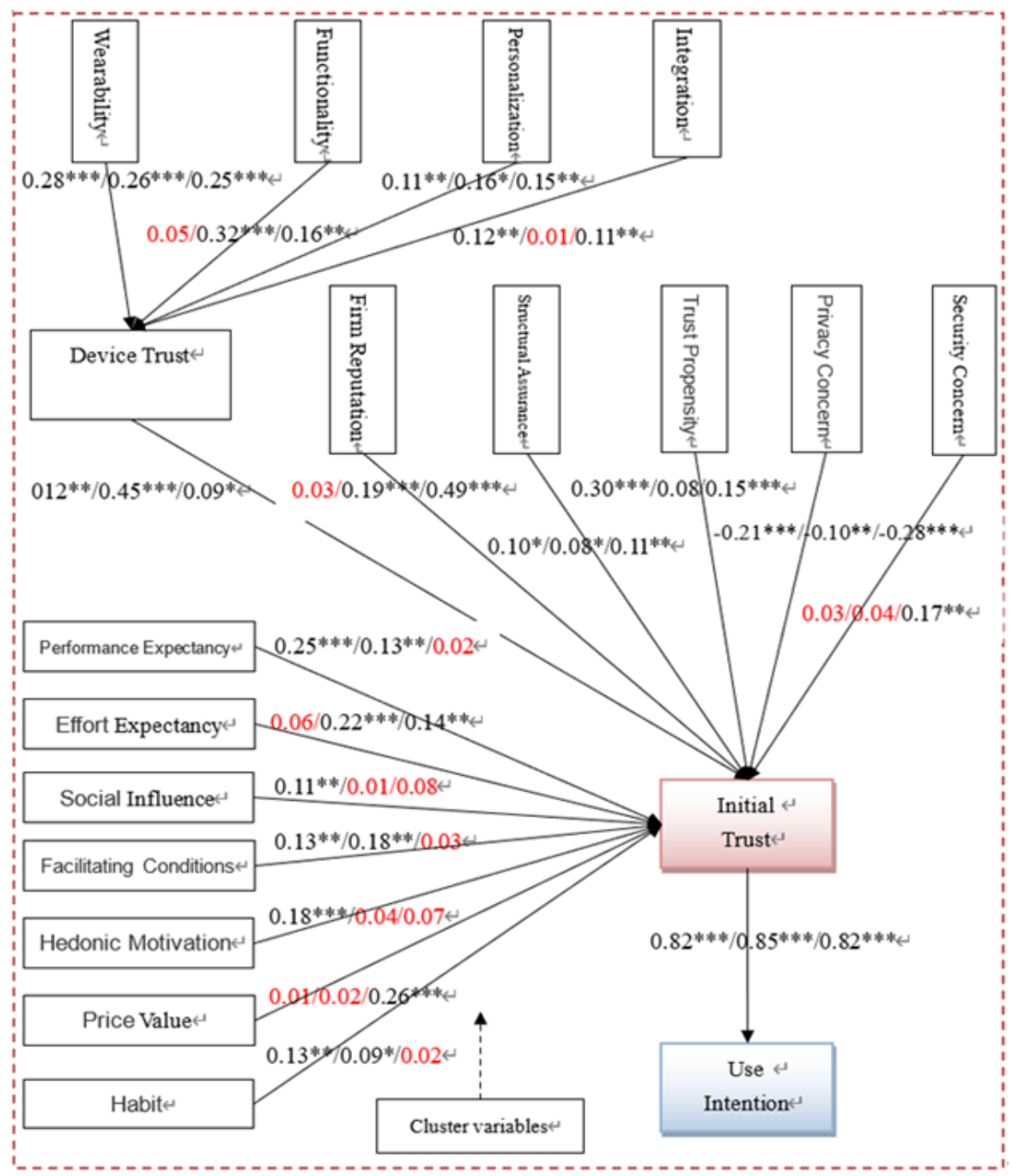

\subsection{Comparison and Analysis of Hypothesis Testing of Different Subgroups}

The standard regression coefficients in Figure 3 and Figure 4 are plotted in Table 8. As can be seen from Table 8, for consumers with different lifestyles, the strength of the relationship between variables in the model still changes, but the basic direction does not change greatly.

A specific comparative analysis of each hypothesis is given below:

H1: Device trust significantly affects consumers' initial trust in wearable services.

According to the calculation results of the structural equation model, it can be found that the path coefficients of three subgroups for $\mathrm{H} 1$ are $0.28,0.26$ and 0.25 respectively. $\mathrm{H} 1$ is significantly true for fashion-leading consumers, but not for the other two types of consumers, and there is a significant difference between fashion-leading consumers and the other two types of consumers. 
H1a: Wearability significantly affects consumers' trust in wearable devices.

It can be found that the path coefficients of three subgroups for H1a are $0.28,0.26$ and 0.25 respectively. At the significance level of 0.001 above, H1a is true for all three subgroups, but there is no difference between them.

H1b: Functionality significantly affects consumers' trust in wearable devices.

It can be found that the path coefficients of three subgroups for H1b are 0.05, 0.32, 0.16. H1b is true for fashion-leading consumers, but not for the other two types of consumers, and there is a significant difference between fashion-leading consumers and the other two types of consumers.

H1c: Personalization has a significant impact on consumers' trust in wearable devices.

It can be found that the path coefficients of three subgroups for H1c are $0.11,0.16,0.15$. At the significance level of 0.01 above, H1c is true for three types of consumers, but there is no significant difference between each other.

H1d: Integration significantly affects consumers' trust in wearable devices.

It can be found that the path coefficients of three subgroups for H1d are $0.12,0.01,0.11$. H1d is true for trend-following and economic-rational consumers, but not for fashion-leading consumers. There is a significant difference between fashion-leading consumers and other two types of consumers.

H2: The reputation of the Firm has a significant impact on the initial trust of wearable services.

It can be found that the path coefficients of three subgroups for $\mathrm{H} 2$ are $0.03,0.19,0.49$. H1d is valid for fashion-leading and economic-rational consumers, but not for trend-following users. There is a significant difference between trend-following users and the other two types.

H3: Structural assurance will positively affect consumers' initial trust in wearable services.

It can be found that the path coefficients of three subgroups for $\mathrm{H} 3$ are $0.10,0.08$ and 0.11 respectively. At the significance level of 0.05 above, $\mathrm{H} 3$ is valid for all the three types of consumers, but there is no significant difference between them.

H4: Consumers' trust propensity significantly affects initial trust in wearable services.

It can be found that the path coefficients of three subgroups for $\mathrm{H} 3$ are $0.30,0.08$ and 0.15 respectively. At the significance level is of $0.001,0.05$ and 0.01 above, $\mathrm{H} 4$ is true for all the three types of consumers, but there are differences among them.

H5: Privacy concerns negatively affect consumers' initial trust in wearable services.

It can be found that the path coefficients of three subgroups for H5 are $-0.21,-0.10$ and -0.28 respectively. At the significance level is $0.001,0.05$ and 0.001 above respectively, $\mathrm{H} 5$ is valid for all the three types of consumers, but there are differences among them. 
H6: Security concerns negatively affect consumers' initial trust in wearable services.

It can be found that the path coefficients of three subgroups for H6 are $0.03,0.04,0.17$. Only the significance level of economical-rational type is at 0.01 above. H6 is valid for economical-rational type, the other two types are not valid, and there are significant differences between them.

H7: Performance Expectancy have a positive impact on consumers' initial trust in wearable services.

It can be found that the path coefficients of three subgroups for $\mathrm{H} 7$ are $0.25,0.13,0.02 . \mathrm{H} 7$ is true for trend-following and fashion-leading consumers, but not for economical-rational, with significant differences between them.

H8: Efforts are expected to positively affect consumers' initial trust in wearable services.

It can be found that the path coefficients of three subgroups for $\mathrm{H} 8$ are $0.06,0.22,0.14 . \mathrm{H} 8$ is true for fashion-leading and economical-rational users, but not for trend-following users, and there are significant differences between them.

H9: Social influence positively affects consumers' initial trust in wearable services.

It can be found that the path coefficients of three subgroups for H9 are $0.11,0.01$ and 0.08 respectively. $\mathrm{H} 9$ is true for trend-following type and economical-rational type, but not for fashionleading type.

H10: Facilitating Conditions positively affect consumers' initial trust in wearable services.

It can be found that the path coefficients of three subgroups for $\mathrm{H} 10$ are $0.13,0.18,0.03$. H10 is true for trend-following type and fashion-leading type, but not for economical-rational type.

H11: Hedonic motivation positively affects consumers' initial trust in wearable services.

It can be found that the path coefficients of three subgroups for H11 are 0.18, 0.04 and 0.07 respectively. $\mathrm{H} 11$ is true for trend-following type, but not for fashion-leading and economical-rational type.

H12: Price value negatively affects consumers' initial trust in wearable services.

The path coefficients of three subgroups for $\mathrm{H} 12$ are $0.01,0.02$ and 0.26 respectively. $\mathrm{H} 12$ is true for economical-rational consumers, but not for trend-following consumers and fashion-leading consumers.

H13: Habits positively affect consumers' initial trust in wearable services.

The path coefficients of three subgroups for $\mathrm{H} 13$ are $0.13,0.09$ and 0.02 respectively. $\mathrm{H} 13$ is true for trend-following consumers, but not for fashion-leading and economical-rational type.

H14: Consumers' initial trust positively affects consumers' use intention in wearable services. 
The path coefficients of three subgroups for $\mathrm{H} 14$ are $0.82,0.85,0.82$ respectively. At the level 0.001 above, $\mathrm{H} 14$ is true for all three types of consumers, it indicates that initial trust is a predictive variable of consumers' use intention, but there is no significant difference among them.

To sum up, the influencing factors of the three types of consumers' initial trust are significantly different.

\section{CONCLUSIONS AND PROSPECTS}

\subsection{Conclusions}

This paper combines demographic variables, personality characteristics and motivation factors to cluster users of wearable services. The trust and willingness of consumers to use wearable services in each cluster are analyzed and compared. Through an improved clustering algorithm based on adaptive chaotic particle swarm optimization, consumers are grouped into three types of consumers with different lifestyles, which are named as trend-following users, fashion-leading users and economicalrational users. Through the analysis and comparison of consumer trust models of wearable services for three subgroups, some important conclusions can be drawn:

For trend-following users, trust propensity, privacy concern, performance expectancy and hedonic motivation are the most important factors affecting consumers' initial trust. Device trust, social influence, facilitating conditions, habits and other factors are also important. Wearability is the most important antecedent variable of device trust, followed by personalization and integration, while functionality is not very important. This indicates that such users are willing to trust the recommendation of other authoritative persons, and expect that wearable services can bring them work efficiency improvement and happy life convenience.

For fashion-leading users, device trust, firm reputation and effort expectancy are the most important factors affecting consumers' initial trust, as well as privacy concern, performance expectancy and facilitating conditions. The most important antecedent variables of device trust are wearability and functionality, followed by personalization, while integration is not so important. It shows that such users are willing to try hard and be more fashionable and willing to try as long as they have trust in the products of the merchants.

For economic-rational users, firm reputation, trust propensity, privacy concern and price value are the most important factors affecting consumers' initial trust, and structural assurance, security concern and effort expectancy are also important. Wearability is also the most important antecedent variable of device trust, but functionality, personalization and integration are also important. This indicates that economic-rational consumers are sensitive to price, care more about brand reputation and safety issues of merchants, and have high expectations for wearable devices.

\subsection{Limitations and Prospects}

\section{Limitations}

This paper has been tracking wearable devices and their business applications since the first year of wearable Devices in 2012.As an exploratory research, although some work has been done in this paper, the selected research object is relatively new, the research difficulty is high, the research depth is not deep enough, and there are limitations in the following aspects:

(1) The quality of research samples needs to be improved.

Due to the large number of items involved in this study, the difficulty is relatively large, the questionnaire is too long, and the selection range of sample survey objects is narrow, most of them are concentrated in Colleges and high-tech industries, and the respondents may not represent all the 
consumers and potential consumers of wearable services, which may reduce the external validity of this study and lead to the lack of inference ability.

(2) Insufficient depth and breadth of research content.

Although this paper spent a lot of time to study the initial trust model of wearable services, and through the clustering of users, empirical analysis and comparison of the differences of trust between different subgroups, but in view of the limited research space, time and energy, the depth and breadth of this study need to be improved. There is no more in-depth empirical and quantitative research on the influencing factors of consumer adoption behavior of wearable services. Many fields, especially the establishment of the concept system of wearable services, device trust of wearable services, privacy security issues and other research topics are worthy of in-depth exploration. It is hoped that this paper can attract more scholars to join the research, so as to promote the development of Wearable service theory and practice.

\section{Prospects}

Looking ahead, wearable services have great potential for development. With the gradual maturity of wearable devices and their environment, wearable services have a very broad prospect. Wearable services will benefit not only network operators, but also device providers, content providers, service providers and consumers. The most important thing is that the whole manufacturing industry can seize the development opportunity of Internet of Things and truly realize the unification of industrialization and informatization.

From a practical point of view, the research in this paper can provide suggestions and guidance for wearable service providers to help them better design products and create better market conditions for the development of wearable services.

First of all, we need to establish a sound mechanism to protect consumers' privacy and enhance consumers' confidence in the privacy protection of wearable services. How to regulate the behavior of consumer information collection in the process of using wearable devices, how wearable device providers use the collected information without infringing consumers' privacy, and how to ensure consumers' privacy without losing the convenience brought by wearable services, etc. Therefore, wearable device providers need to pay attention to consumer privacy and security issues, abide by the relevant privacy provisions, ensure the openness and transparency of information collection and use, and establish a good corporate image.

Secondly, in the design of wearable devices, we need to pay attention to the wearability, functionality and hedonism of wearable devices, and pay attention to improving the consumer experience. With the development of technology, consumers have a strong demand for the pleasure and happiness brought by using novel devices, and they pay more and more attention to the use experience. Due to the low awareness of wearable devices among consumers, enterprises should strengthen their awareness of wearable devices. 


\section{REFERENCES}

Gu, Z., \& Wei, J. (2020). Wearable Services Adoption Study from a Perspective of Usability. Lecture Notes in Computer Science, 12216, 16-22.

Hawkins, D. I., \& Matheson, D. L. (2011). Consumer behavior: building marketing strategy. China Machine Press.

Wang, G., Hui, T., \& Hong, W. (2013). Consumer psychology (2nd ed.). Electronic Industry Press.

Hoyle, W. D., \& McInnis, D. J. (2010). Consumer behavior: An application guide for advertising and marketing professionals. China Marketing Press.

Luo, Z. (2007). Consumer psychology (3rd ed.). Tsinghua University Press.

Gu \& Xu. (2015). Clustering algorithm based on adaptive chaotic particle swarm optimization. Computer Engineering and Design, (6), 1510-1513.

Gu, Z. (2017). Research on Consumers' Initial Trust. In Wearable Commerce. University of Shanghai for Science and Technology.

Gu, Z., Wei, J., \& Xu, F. (2016). An Empirical Study on Factors Influencing Consumers' Initial Trust in wearable Commerce. Journal of Computer Information Systems, 56(1), 79-85.

Yang, Gu, \& Wei. (2020). An Empirical Research on Factors Influencing Virtual Community Members Shift Toward E-Commerce Buyers. Design, Operation and Evaluation of Mobile Communications.

Gu, Z., \& Wei, J. (2020). Empirical Study on Initial Trust of wearable Devices Based on Product Characteristics. Journal of Computer Information Systems. Advance online publication. doi:10.1080/08874417.2020.1779150

Sarah, R. E. (2012). Wearable Devices: The Next Battleground for the Platform Wars. Forrester Survey. http:// blogs.forrester.com

Hao, H. (2014). Analysis of trust change in the process of mobile content service adoption. Management Review, 26(4), 122-129.

Gefen, D. (2000). E-commerce: The Role of Familiarity and Trust. Omega, 28(6), 725-737.

Junglas, I. A., \& Watson, R. T. (2006). The U-Constructs: Four Information Drives. Communications of Ais, $17,569-592$.

McKnight, D. H., Choudhury, V., \& Kacmar, C. (2002b). The impact of initial consumer trust in intentions to transact with a web site: A trust building model. The Journal of Strategic Information Systems, 1, 473-490.

IResearch. (2013). China wearable device. Market Research Report. http://www.iresearch.cn

Wu, I. L., \& Chen, J. L. (2005). An Extension of Trust and Tam Model with Tpb in the Initial Adoption of OnLine Tax: An Empirical Study. International Journal of Human-Computer Studies, 62(6), 784-808.

Nysveen, H., Pedersen, P. E., \& Thorbjørnsen, H. (2005). Intentions to use mobile services: Antecedents and cross- service comparisons. Journal of the Academy of Marketing Science, 33(3), 330-346.

Min, Q. (2008). Research on trust factors of mobile commerce adoption. Guanli Shijie, (12), 184-185.

Baidu Research Report on wearable devices. (2013). http://www.baidu.com

Venkatesh, V., Thong, J., \& Xu, X. (2012). Consumer Acceptance and Use of Information Technology: Extending the Unified Theory of Acceptance and Use of Technology. Management Information Systems Quarterly, 36(1), $157-178$.

Chan, K. Y., Gong, M., \& Xu, Y. (2008). Examining user acceptance of SMS: An empirical study in China and Hong Kong. Pacific Asia Conference on Information Systems, Pacis 2008, 294.

Lee, S., \& Lee, E. (2007). A collective User Preference Management System for U-Commerce. Managing Next Generation Networks and Services. 
Jin, B. K. (2012). An Empirical Study on Consumer First Purchase Intention in Online Shopping: Integrating Initial Trust and Tam. Electronic Commerce Research, 12(2), 125-150.

Zeithaml, V. A. (1988). Consumer Perceptions of Price, Quality, and Value: A Means-End Model and Synthesis of Evidence. Journal of Marketing, 52(3), 2-22.

Tao, Z. (2014). An Empirical Examination of Initial Trust in Mobile Payment. Wireless Personal Communications, 77(2), 1519-1531.

Limayem, M., Hirt, S. G., \& Cheung, C. M. K. (2007). How Habit Limits the Predictive Power of Intentions: The Case of IS Continuance. Management Information Systems Quarterly, 31(4), 705-737.

Ma, Q. (2012). Research on the influence mechanism of customer initial trust in C2C environment: The moderating effect of online shopping experience. Management Review, 24(7), 70-81.

Sang, M. L., Sang, H. P., \& Seong, N. Y. (2007). RFID Based Ubiquitous Commerce and Consumer Trust. Industrial Management \& Data, 107(5), 605-617.

Liao, C., Palvia, P., \& Lin, H. N. (2006). The roles of habit and web site quality in e-commerce. International Journal of Information Management, 26(6), 469-483.

Lin, J., \& Lu, Y. (2011). Research on the initial trust model of Mobile Securities users. Management Review, 23(11), 59-68.

Lu, J., Yu, C. S., \& Liu, C. (2005). Facilitating Conditions, Wireless Trust and Adoption Intention. Journal of Computer Information Systems, 46(1), 17-24.

Pahnila, S., Siponen, M., \& Zheng, X. (2011). Integrating Habit into UTAUT: The Chinese eBay Case. Pacific Asia Journal of the Association for Information Systems.

$\mathrm{Hu}$, Liu, Zhao, \& Du. (2018). A path detecting method to analyze the interactive compatibility of service processes based on WS-BPEL. Concurrency and Computation: Practice and Experience, 30(19).

Hu, Q., \& Shen, J. (2020). A Cluster and Process Collaboration-Aware Method to Achieve Service Substitution in Cloud Service Processes. Scientific Programming.

\section{ENDNOTE}

Weka, whose full name is Waikato Environment for Knowledge Analysis, is a free, non-commercial software (corresponding to SPSS's commercial data mining product-Clementine), machine learning based on JAVA Environment and data Mining software.

Gu Zhongwei, Male, an Anhui Huainan native (1977-), got his doctor degree from University of Shanghai for Science and Technology and got his master degree from Zhejiang University. Now He is a lecturer in the School of Business at Shanghai Dianji University. His research interests include Quality Management based on Bigdata, E-commerce, etc.

Hongjun Xiong, Male, a Hunan native (1978-), got his doctor degree from Donghua University. Now he is an associate professor in the School of Business at Shanghai Dianji University. His research interests include Management Information Systems, E-commerce, etc.

Wei Hu, Male, a Hubei native (1979-), is a professor in the School of Business at Shanghai University of Electric Power. His research interests include Management Information Systems, Energy block chain, etc. 